\title{
PROFILE: CELESTE ORAM
}

I'm fascinated by the loose affiliation of alleluias' that make up the violin concerto that was premiered in 2019. But how 'loose' is it? What are the elements of this music?

I guess it's 'loose' in a similar sense to where the phrase comes from - the Paul Simon lyric about 'a loose affiliation of millionaires and billionaires'. Some of those

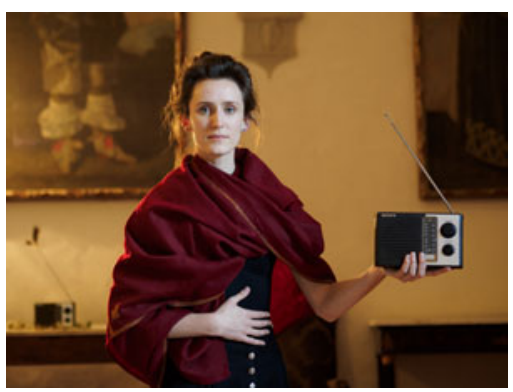

Celeste Oram millionaires and billionaires are undoubtedly in close cahoots; others are complete strangers but are still entwined by virtue of being bound up in the fate and interests of global capitalism. In the musical sense, it's an affiliation where some connections are very clear, and others take a bit of unriddling - or at least a lot of zooming out - to start to see them.

As for musical elements, perhaps the piece's most recognisable/anachronistic inhabitants are bits of early Euro-Christian church music: there's a two-voice hymn from the twelfth-century Codex Callixtinus, some fragments from one of Giovanni Gabrieli's early-seventeenth-century sacred symphonies, 'Exaudi me domine', and a handful of stray alleluias from Gregorian chant. The solo violin part, played by Keir GoGwilt, is basically improvised: Keir draws on (among other things) eighteenth-century European techniques to extemporise on harmonic templates. And the whole thing sits inside the hollowed-out, strung-out shell of an 80s pop song: it goes intro-verse-chorus-instrumental-verse-chorus-bridgechorus-outro-fade - and there's some lingering detritus of booming backbeats, like 80 s drum reverb that's finally coming back to us after a few moon bounces. And the backstage singers croon 'don't cry, baby, don't cry, don't cry', as Paul Simon has also been known to do.

This piece was very much inspired and emboldened by the music of Cassandra Miller. I love how she works with existing music: music that clearly means a lot to her personally (even if that attraction is a little inexplicable), and so in composing with that music she kind of excavates and ponders what is so alluring about it. So, at the level of process, I began this piece by similarly thinking, OK, let's get together a little compost pile of music, and see what grows out of it.

How does the music that you 'grow' relate to the different places in which it might be heard? You're from New Zealand, your music has been well received in parts of mainland Europe and you are currently based in California. Do you think about geography and culture when you are making or listening to music?

Yes, absolutely; when I am making and listening to music I think a lot about geography and culture - and history, too. Historical materialism is kind of a bottom line for me when it comes to understanding music, right down to the disciplinary knowledge or embodied technique that structure what might seem like very personal musical decisions or 
tastes. In every project I work on I'm trying to pick through the scenario of where, when, how, why and with whom this music will happen, and take the long historical view of how those conditions came about. My own biography - growing up as a settler in Aotearoa New Zealand, studying as a settler in California and producing culture that is somehow legible in Europe - is obviously not just an accident of birth, or a personal journey, but enabled by centuries of colonial invasion and occupation. In that sense, those cultural/institutional networks and historical conditions are my instrument, for better or worse: they shape how sound resonates. Which is not necessarily to say that blithely reproducing those same conditions is the only thing for it. But, at the very least, I'm interested in finding ways for my own musical projects to make more visible all the circumstances that make them possible in the first place.

I think we live in a time when the work of people who call themselves composers seems more provisional than perhaps ever before. Are you conscious of this? Does it affect what you do?

Yes, I'd agree, and I do think that applies to the work I've been doing, although I think of my approach as 'responsive' more than 'provisional'. In any given project I try to instrumentalise - musically its particular circumstances and conditions. Often this means thinking of composing not so much for the instruments involved, but for the individuals: an approach I share with many other composers doing so each in their own fruitful way. For me, this has opened up several interesting lines of inquiry: into the genealogies of knowledge and entrainments shaping a particular musician's musicianship; their very personal relationships to their instrument, habits of practice and the economic equations of their professional careers; and how their musical activity is shaped by factors like gender, race, class. The violin concerto I made with Keir GoGwilt is one example of such a tailor-made piece, but I'd also mention others: a couple of recent projects for the Birmingham Contemporary Music Group that had very specific thematic briefs (one for the two-hundredth birthday of Karl Marx); music-theatre pieces made for and with folks like percussionist Steve Schick, taonga pūoro musician Rob Thorne and Autoduplicity (Rachel Beetz and Jennifer Bewerse in Los Angeles) - all performers with very distinctive artistic pursuits and priorities; and various polyphonic songs written for particular singers and occasions (one to be performed at the former home of Barney Ford, a nineteenth-century Colorado businessman born into slavery).

All of those pieces have drawn the inevitable question, 'can someone else perform it somewhere else?'. The answer is always yes (given appropriate consents); it just becomes a different version - like when different actors play the same character - with various adaptations according to the new circumstances. But, to me, that doesn't feel wholly exceptional from the adaptability of musical practices generally. One of my favourite flute sonatas to play growing up (Prokofiev's) was also a violin sonata!

So I'd just push back a bit against that 'now more than ever before' sentiment. We know there are countless instances historically where music was engineered for very specific purposes, or was made for immediate use. Zooming out from the notated European tradition makes that quite obvious. Even the Imaginary Museum of Musical Works formed in response to a particular set of cultural and consumer 
imperatives! It's attending to those very immediate, local conditions around music-making (they're always there) that I find to be most interesting, both historically and contemporaneously. Tuning into the particulars of one performance, rather than restricting its reach or relevance, I find actually allows a much clearer amplification of the transhistorical connections surrounding it. While I can't speak for others, my sense is that this 'responsive' approach to music-making that I share with so many wonderful colleagues - trying to seek out incredibly personal inflections of historical materials - is not so much an exercise in modernist flag-planting (who got there first), but all part of the project to chip away at the hierarchies and hegemonies in the musical practices we inherit. The more one insists on the value (the necessity!) of the thoroughly personal and provincial, the more power is ceded to the margins.

Coming from quite a different angle, though, the first thing your question in fact made me think of was that the current pandemic has made so apparent how the work of many composers (myself included) is provisional in the sense of being bound up in institutional patronage. I mean, we knew that theoretically... but this past year I've palpably felt it, or, rather, felt the absence of all that. If it's not for the academia-supported concertising or the carefully curated festivals - when all that is suspended - then what actually is your instrument? What is the outlet for your musicianship? HOW do you MUSIC? Who and what is it for? Is it singing Joni Mitchell covers on the porch for my neighbours? Is it making little recordings of flute and piano pieces to cheer up my mum? Because that's a far, far cry from the musicianship in which I have invested years apparently trying to develop some kind of expertise. Of course, so many musicians moonlight in weird and wonderful ways, but I hope many in our field come out the other side of this pandemic having reckoned more frankly with the question of who and what exactly one's professional work is cultivated to serve. That's not necessarily a 'gotcha' question. I just think it's important to be able to answer it straight. 